\title{
SIMULATION MODEL OF AN ASYNCHRONOUS MACHINE WITH WOUND ROTOR IN MATLAB SIMULINK
}

\author{
Igor Doroshchenko ${ }^{1, *}$, Vladimir Zakharenko ${ }^{1}$, and Mikhail Pohulayev ${ }^{1}$, Nailya Miftakhova $^{2}$ \\ ${ }^{1}$ Sukhoi State Technical University of Gomel, Automation and Information Systems Faculty, 246746, Prospect Octiabria, 48, Gomel, \\ Republic of Belarus \\ ${ }^{2}$ Kazan State Power Engineering University, 420066, ul. Krasnoselskaya 51, Kazan, Russia
}

\begin{abstract}
The article presents a three-phase mathematical model of asynchronous machine with wound rotor based on differential equations. The equations are resolved with respect to the derivatives of flux linkages. The description of the computer program in the Matlab Simulink that implements the model and allows to simulate transients of the asynchronous motor is present. A simulation model of a three-phase asynchronous machine with wound rotor, which allows to investigate static and dynamic operating ranges when power converters are connected to the rotor circuit has been obtained. The results of approbation of the obtained simulation model in the Matlab Simulink environment and experimental research of asynchronous engine with wound rotor, driving into the asynchronous-valve cascade, are presented. The results of experimental studies of the asynchronous machine under sinusoidal voltage using a stand based on the asynchronous-valve cascade, and comparison of the oscillograms obtained with simulation results of the proposed model are presented. The comparison of experimental and calculated oscillograms of the current of the investigated asynchronous motor can be concluded on satisfactory accuracy of the proposed model and the possibility of its application for modeling and analysis of asynchronous electric drives.
\end{abstract}

\section{Introduction}

In engineering practice, mathematical models built on the basis of a generalized two-phase electric machine are used for analysis and synthesis of electric drive systems based on asynchronous machines with controlled converters [1-3]. Traditional modeling of electric drives is carried out in software packages Matlab Simulink, VisSim, etc., however, they are compiled either on the basis of a two-phase mathematical model of an asynchronous machine, or a three-phase mathematical engine model in a natural coordinate system directed along the axes of the phase stator windings, which is valid only for the connection diagram of the windings stator and rotor "star with neutral" [2-6]. To analyze asynchronous electric drives in the Matlab Simulink software package, a basic simulation model of an induction machine with wound rotor is used. It's based on a two-phase asynchronous machine of a mathematical model, which has the following disadvantages:

- the model cannot work when the rotor is open;

- the two-phase model, on the basis of which the basic asynchronous machine was developed in Matlab Simulink, does not exactly reflect the shape, amplitude and frequency of oscillatory components in dynamic modes (these parameters for models of a two-phase and three-phase machine will be different [1]);

- the calculation is not performed adequately when power converters are included in the rotor circuit (especially if a high resistance arises in the rotor circuit during simulation, which is typical with closed valves of power converters in the rotor circuit).

Therefore, the urgent task is to create a simulation model of an induction machine with phase-wound rotor, which would most fully reflect the electromechanical transformations.

The purpose of the work is to create a simulation model that allows to study a three-phase asynchronous machine with phase-wound rotor when power converters are connected to the rotor circuit.

\section{Main part}

A three-phase mathematical model of an asynchronous machine in an unconverted system in the phase axes of coordinates A, B, C, a, b, c, we compose according to the sources $[2,3]$. Solutions of the equations of the mathematical model will be determined through the derivatives of flux linkages. To do this, we write down the equations for the derivatives of flux linkages, expressed through the parameters of the stator $i_{\mathrm{A}}, i_{\mathrm{B}}, i_{\mathrm{C}}$, rotor currents $i_{a}, i_{b}, i_{c}$, inductances $L_{1}, L_{2}, L_{12}$ and the rotor rotation angle $\varphi_{\text {r. }}$.

Using expressions for the electromagnetic moment of the generalized electric machine and the equation of the mechanical part [1-3], we obtain the system (1).

\footnotetext{
* Corresponding author: $\underline{\mathrm{dr}-\mathrm{aed} @ \text { yandex.ru }}$
} 


$$
\begin{aligned}
& \int \frac{\mathrm{d} \psi_{A}}{\mathrm{dt}}=L_{1} \cdot \frac{\mathrm{d} i_{A}}{\mathrm{dt}}-\frac{L_{12}}{2} \cdot \frac{\mathrm{d} i_{B}}{\mathrm{dt}}-\frac{L_{12}}{2} \cdot \frac{\mathrm{d} i_{C}}{\mathrm{dt}}+L_{12} \cdot \cos \left(\varphi_{\mathrm{r}}\right) \cdot \frac{\mathrm{d} i_{a}}{\mathrm{dt}}-L_{12} \cdot \sin \left(\varphi_{\mathrm{r}}\right) \cdot \omega_{\mathrm{r}} \cdot i_{a}+L_{12} \cdot \cos \left(\varphi_{\mathrm{r}}-\frac{2 \cdot \pi}{3}\right) \cdot \frac{\mathrm{d} i_{b}}{\mathrm{dt}}- \\
& -L_{12} \cdot \sin \left(\varphi_{\mathrm{r}}-\frac{2 \cdot \pi}{3}\right) \cdot \omega_{\mathrm{r}} \cdot i_{b}+L_{12} \cdot \cos \left(\varphi_{\mathrm{r}}+\frac{2 \cdot \pi}{3}\right) \cdot \frac{\mathrm{d} i_{c}}{\mathrm{dt}}-L_{12} \cdot \sin \left(\varphi_{\mathrm{r}}+\frac{2 \cdot \pi}{3}\right) \cdot \omega_{\mathrm{r}} \cdot i_{c} \\
& \frac{\mathrm{d} \psi_{B}}{\mathrm{dt}}=L_{1} \cdot \frac{\mathrm{d} i_{B}}{\mathrm{dt}}-\frac{L_{12}}{2} \cdot \frac{\mathrm{d} i_{A}}{\mathrm{dt}}-\frac{L_{12}}{2} \cdot \frac{\mathrm{d} i_{C}}{\mathrm{dt}}+L_{12} \cdot \cos \left(\varphi_{\mathrm{r}}\right) \cdot \frac{\mathrm{d} i_{b}}{\mathrm{dt}}-L_{12} \cdot \sin \left(\varphi_{\mathrm{r}}\right) \cdot \omega_{\mathrm{r}} \cdot i_{b}+L_{12} \cdot \cos \left(\varphi_{\mathrm{r}}-\frac{2 \cdot \pi}{3}\right) \cdot \frac{\mathrm{d} i_{c}}{\mathrm{dt}}- \\
& -L_{12} \cdot \sin \left(\varphi_{\mathrm{r}}-\frac{2 \cdot \pi}{3}\right) \cdot \omega_{\mathrm{r}} \cdot i_{c}+L_{12} \cdot \cos \left(\varphi_{\mathrm{r}}+\frac{2 \cdot \pi}{3}\right) \cdot \frac{\mathrm{d} i_{a}}{\mathrm{dt}}-L_{12} \cdot \sin \left(\varphi_{\mathrm{r}}+\frac{2 \cdot \pi}{3}\right) \cdot \omega_{\mathrm{r}} \cdot i_{a} \\
& \frac{\mathrm{d} \psi_{C}}{\mathrm{dt}}=L_{1} \cdot \frac{\mathrm{d} i_{C}}{\mathrm{dt}}-\frac{L_{12}}{2} \cdot \frac{\mathrm{d} i_{B}}{\mathrm{dt}}-\frac{L_{12}}{2} \cdot \frac{\mathrm{d} i_{A}}{\mathrm{dt}}+L_{12} \cdot \cos \left(\varphi_{\mathrm{r}}\right) \cdot \frac{\mathrm{d} i_{c}}{\mathrm{dt}}-L_{12} \cdot \sin \left(\varphi_{\mathrm{r}}\right) \cdot \omega_{\mathrm{r}} \cdot i_{c}+L_{12} \cdot \cos \left(\varphi_{\mathrm{r}}-\frac{2 \cdot \pi}{3}\right) \cdot \frac{\mathrm{d} i_{a}}{\mathrm{dt}}- \\
& -L_{12} \cdot \sin \left(\varphi_{\mathrm{r}}-\frac{2 \cdot \pi}{3}\right) \cdot \omega_{\mathrm{r}} \cdot i_{a}+L_{12} \cdot \cos \left(\varphi_{\mathrm{r}}+\frac{2 \cdot \pi}{3}\right) \cdot \frac{\mathrm{d} i_{b}}{\mathrm{dt}}-L_{12} \cdot \sin \left(\varphi_{\mathrm{r}}+\frac{2 \cdot \pi}{3}\right) \cdot \omega_{\mathrm{r}} \cdot i_{b} \\
& \frac{\mathrm{d} \psi_{a}}{\mathrm{dt}}=L_{12} \cdot \cos \left(\varphi_{\mathrm{r}}\right) \cdot \frac{\mathrm{d} i_{A}}{\mathrm{dt}}-L_{12} \cdot \sin \left(\varphi_{\mathrm{r}}\right) \cdot \omega_{\mathrm{r}} \cdot i_{A}+L_{12} \cdot \cos \left(\varphi_{\mathrm{r}}+\frac{2 \cdot \pi}{3}\right) \cdot \frac{\mathrm{d} i_{C}}{\mathrm{dt}}-L_{12} \cdot \sin \left(\varphi_{\mathrm{r}}+\frac{2 \cdot \pi}{3}\right) \cdot \omega_{\mathrm{r}} \cdot i_{C}+ \\
& +L_{12} \cdot \cos \left(\varphi_{\mathrm{r}}-\frac{2 \cdot \pi}{3}\right) \cdot \frac{\mathrm{d} i_{B}}{\mathrm{dt}}-L_{12} \cdot \sin \left(\varphi_{\mathrm{r}}-\frac{2 \cdot \pi}{3}\right) \cdot \omega_{\mathrm{r}} \cdot i_{B}+L_{2} \cdot \frac{\mathrm{d} i_{a}}{\mathrm{dt}}-\frac{L_{12}}{2} \cdot \frac{\mathrm{d} i_{b}}{\mathrm{dt}}-\frac{L_{12}}{2} \cdot \frac{\mathrm{d} i_{c}}{\mathrm{dt}} \\
& \left\{\frac{\mathrm{d} \psi_{b}}{\mathrm{dt}}=L_{12} \cdot \cos \left(\varphi_{\mathrm{r}}\right) \cdot \frac{\mathrm{d} i_{B}}{\mathrm{dt}}-L_{12} \cdot \sin \left(\varphi_{\mathrm{r}}\right) \cdot \omega_{\mathrm{r}} \cdot i_{B}+L_{12} \cdot \cos \left(\varphi_{\mathrm{r}}+\frac{2 \cdot \pi}{3}\right) \cdot \frac{\mathrm{d} i_{A}}{\mathrm{dt}}-L_{12} \cdot \sin \left(\varphi_{\mathrm{r}}+\frac{2 \cdot \pi}{3}\right) \cdot \omega_{\mathrm{r}} \cdot i_{A}+\right. \\
& +L_{12} \cdot \cos \left(\varphi_{\mathrm{r}}-\frac{2 \cdot \pi}{3}\right) \cdot \frac{\mathrm{d} i_{C}}{\mathrm{dt}}-L_{12} \cdot \sin \left(\varphi_{\mathrm{r}}-\frac{2 \cdot \pi}{3}\right) \cdot \omega_{\mathrm{r}} \cdot i_{C}+L_{2} \cdot \frac{\mathrm{d} i_{b}}{\mathrm{dt}}-\frac{L_{12}}{2} \cdot \frac{\mathrm{d} i_{a}}{\mathrm{dt}}-\frac{L_{12}}{2} \cdot \frac{\mathrm{d} i_{c}}{\mathrm{dt}} ; \\
& \frac{\mathrm{d} \psi_{c}}{\mathrm{dt}}=L_{12} \cdot \cos \left(\varphi_{\mathrm{r}}\right) \cdot \frac{\mathrm{d} i_{C}}{\mathrm{dt}}-L_{12} \cdot \sin \left(\varphi_{\mathrm{r}}\right) \cdot \omega_{\mathrm{r}} \cdot i_{C}+L_{12} \cdot \cos \left(\varphi_{\mathrm{r}}+\frac{2 \cdot \pi}{3}\right) \cdot \frac{\mathrm{d} i_{B}}{\mathrm{dt}}-L_{12} \cdot \sin \left(\varphi_{\mathrm{r}}+\frac{2 \cdot \pi}{3}\right) \cdot \omega_{\mathrm{r}} \cdot i_{B}+ \\
& +L_{12} \cdot \cos \left(\varphi_{\mathrm{r}}-\frac{2 \cdot \pi}{3}\right) \cdot \frac{\mathrm{d} i_{A}}{\mathrm{dt}}-L_{12} \cdot \sin \left(\varphi_{\mathrm{r}}-\frac{2 \cdot \pi}{3}\right) \cdot \omega_{\mathrm{r}} \cdot i_{A}+L_{2} \cdot \frac{\mathrm{d} i_{c}}{\mathrm{dt}}-\frac{L_{12}}{2} \cdot \frac{\mathrm{d} i_{b}}{\mathrm{dt}}-\frac{L_{12}}{2} \cdot \frac{\mathrm{d} i_{a}}{\mathrm{dt}} \\
& \mathrm{M}=-L_{12} \cdot p \cdot i_{A} \cdot\left[\sin \left(\varphi_{\mathrm{r}}\right) \cdot i_{a}+\sin \left(\varphi_{\mathrm{r}}-\frac{2 \cdot \pi}{3}\right) \cdot i_{b}+\sin \left(\varphi_{\mathrm{r}}+\frac{2 \cdot \pi}{3}\right) \cdot i_{c}\right]- \\
& -L_{12} \cdot p \cdot i_{B} \cdot\left[\sin \left(\varphi_{\mathrm{r}}+\frac{2 \cdot \pi}{3}\right) \cdot i_{a}+\sin \left(\varphi_{\mathrm{r}}\right) \cdot i_{b}+\sin \left(\varphi_{\mathrm{r}}-\frac{2 \cdot \pi}{3}\right) \cdot i_{c}\right]- \\
& -L_{12} \cdot p \cdot i_{C} \cdot\left[\sin \left(\varphi_{\mathrm{r}}-\frac{2 \cdot \pi}{3}\right) \cdot i_{a}+\sin \left(\varphi_{\mathrm{r}}+\frac{2 \cdot \pi}{3}\right) \cdot i_{b}+\sin \left(\varphi_{\mathrm{r}}\right) \cdot i_{c}\right] \\
& \frac{\mathrm{d} \omega_{\mathrm{r}}}{\mathrm{dt}}=\frac{p}{J} \cdot\left(\mathrm{M}-\mathrm{M}_{\mathrm{s}}\right) \\
& \frac{\mathrm{d} \varphi_{\mathrm{r}}}{\mathrm{dt}}=\omega_{\mathrm{r}},
\end{aligned}
$$

$\psi_{\mathrm{A}}, \psi_{\mathrm{B}}, \psi_{\mathrm{C}}, R_{1}, i_{\mathrm{A}}, i_{\mathrm{B}}, i_{\mathrm{C}}-$ flux linkage, active resistance and currents of stator;

$\psi_{a}, \psi_{b}, \psi_{c}, R_{2}, i_{a}, i_{b}, i_{c}-$ flux linkage, active resistance and currents of rotor;

$L_{1}=L_{1 \sigma}+L_{12}-$ self-inductance of the stator phase winding;

$L_{1 \sigma}$ - leakage inductance of the stator phase winding (according to the T-shaped equivalent circuit);

$L_{2}=L_{2 \sigma}^{\prime}+L_{12}-$ self-inductance of the rotor phase winding reduced to the stator; 


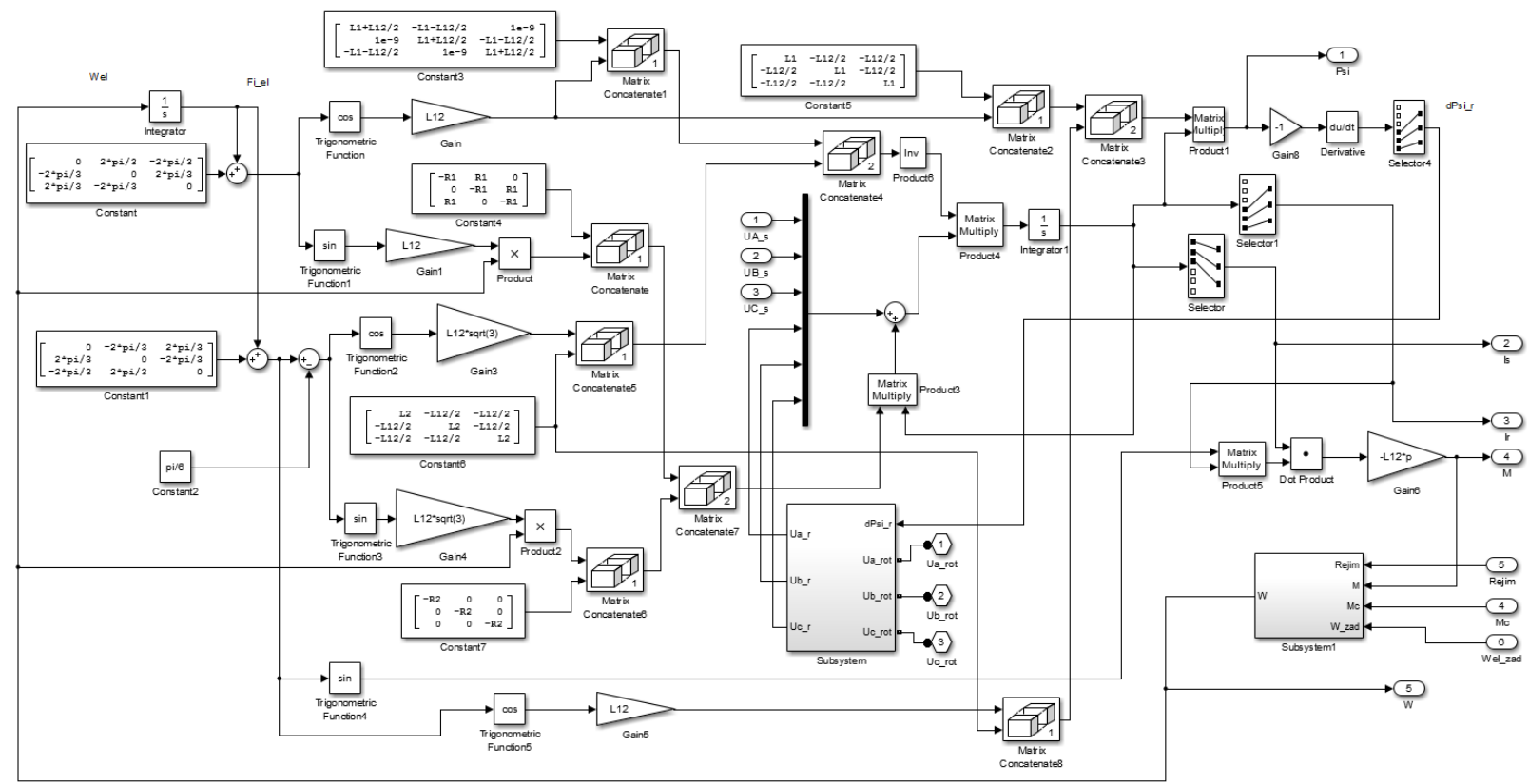

Fig. 1. Model of an induction machine with wound rotor in the Matlab Simulink environment.

which the equations are resolved with respect to the derivatives of flux linkages. Based on the obtained mathematical model of a three-phase asynchronous machine with wound rotor, given the development of similar models [7], a simulation model of a three-phase three-phase asynchronous machine with wound rotor was developed in Matlab Simulink, shown in Fig. 1.

A feature of the developed simulation model of asynchronous machine with wound rotor is that the basic equations of currents and flux linkages are made using blocks of the Simulink library, and the voltage on the rings of phase rotor is determined using elements of the SimPowerSystems library. This allows you to connect various types of load to the phase rotor circuit of the model. Due to the fact that Simulink blocks and SimPowerSystems blocks cannot be directly connected to each other, the Subsystem block is used to convert the SimPowerSystems model into an equivalent computational Simulink model, the content of which is shown in Fig. 2.

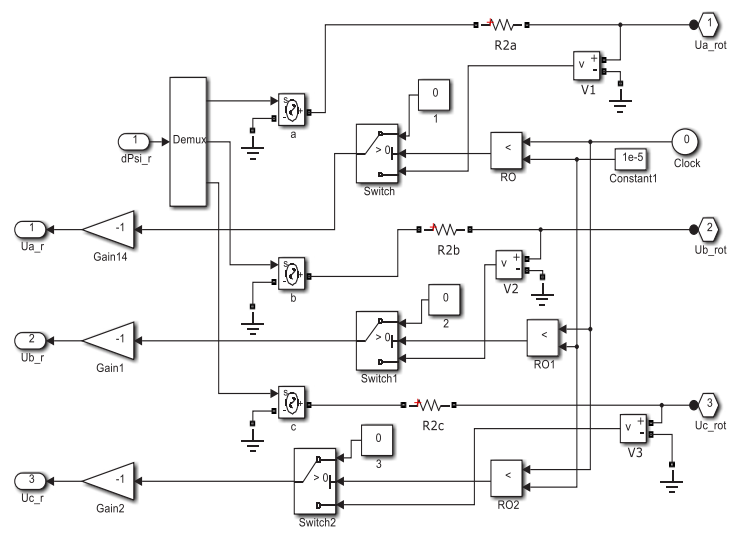

Fig. 2. Contents of the Subsystem block.
The input actions of the simulation model of an induction machine with wound rotor are:

- stator voltage;

- operating mode (engine, generator);

- torque (for engine operation mode) or rotation speed (for generator operation mode).

The output quantities of the model are:

- stator and rotor currents;

- machine rotation speed;

- moment on the machine shaft.

The fig. 3 shows a simulation model of an asynchronous machine with wound rotor (SimPowerSystems-model) in the form of its own unit (Model AD wound rotor) with the connection of the specified input and output values.

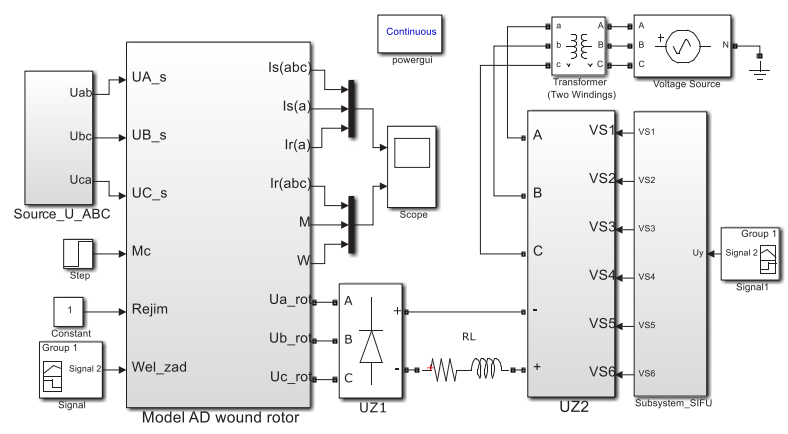

Fig. 3. Simulation model of an asynchronous-valve cascade built on the basis of an asynchronous machine with wound rotor in the Matlab Simulink.

Approbation of the obtained simulation model of an asynchronous machine with wound rotor MTF112-6-U1 with a power of $5 \mathrm{~kW}$ was carried out for an asynchronous valve cascade (fig.3). Calculations and experimental study of currents were carried out at a 
rotation speed of $670 \mathrm{rpm}$ and a load torque of $25 \mathrm{~N} \cdot \mathrm{m}$. Diagrams of stator and rotor phase currents are shown in Fig. 4 and 5 respectively.

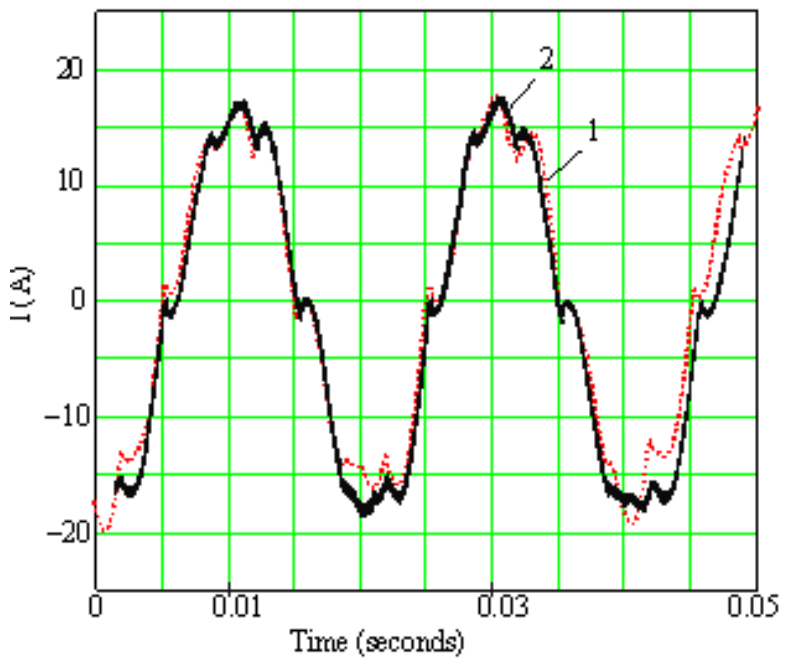

Fig. 4. The form of the phase current of the stator of an asynchronous machine as part of an asynchronous-valve cascade. 1 - calculation; 2 - experiment.

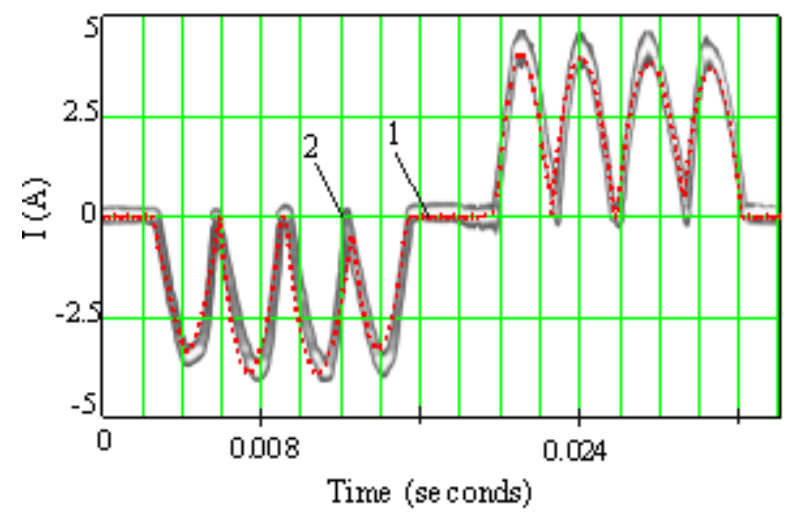

Fig. 5. The form of the phase current of the rotor of an asynchronous machine as part of an asynchronous-valve cascade. 1 - calculation; 2 - experiment.

\section{Conclusion}

The created and debugged simulation model of an asynchronous machine with phase-wound rotor makes it possible to analyze various operating modes of asynchronous machine with wound rotor. In the process of approbation of the simulation model, it was revealed that the calculation step for obtaining an adequate result should be of the order of microseconds-units. This feature is obviously due to the fact that when differentiating the expressions of flux linkages, in order to avoid excessive complication of the model, it was not taken into account that the rotation speed is a function of time, and to obtain an adequate result, the frequency corresponding to the calculation step must be large enough compared to rotor speed.

As a result of comparing the experimental and calculated data, the error in the average value of the currents is no more than $5 \%$, the error in the amplitude of the instantaneous value of the stator and inverter currents is about $7 \%$. Thus, the presented simulation model is advisable to use when compiling simulation models and designing industrial electric drives, which include asynchronous machines with wound rotor.

\section{References}

1. B.I. Firago, L.B. Pavlyachik, Theory of electric drive (2004)

2. I.P. Kopylov. Mathematical modeling of electrical machines 3 (2001)

3. I.P. Kopylov, B.K. Klokov, V.P. Morozkin, B.F. Tokarev Proyektirovaniye elektrycheskykh mashin [The design of electric machines], Moscow (2015)

4. A.V. Shestakov, Modeling and experimental analysis of dynamic characteristics of the asynchronous motor, Russian Internet Journal of Electrical Engineering, 6, 1 (2019)

5. A.V. Shestakov, A.A. Fominykh, Modeling of control processes of the asynchronous motor under pulsating mode with due regard for the influence of real factors, Dynamics of Systems, Mechanisms and Machines" (Dynamics), IEEE Xplore Digital Library, Omsk, Russia (2017)

6. V.I. Kosmatov, A.S. Sarvarov, E.I. Danilov. Mathematical model of energy-saving asynchronous motor in the rotating coordinates system, 17th International Ural Conference on AC Electric Drives (ACED), IEEE Xplore Digital Library, Ekaterinburg, Russia (2018)

7. V.S. Zakharenko, I.V. Doroshchenko, Specific features of simulation modeling of asynchronous motor for making a model allowing for switching with asymmetrical closed circuits also, Bulletin of the Sukhoi State Technical University of Gomel, 3 (46) (2011)

8. S.G. German-Galkin, An analytic and simulation study of a wound-rotor asynchronous machine at positive slides, Russian Electrical Engineering, 7 (86), (2015)

9. Y. Sun, J. Hu, C. Li, Research on power generation control of anynchronous machine as main generator, International journal of emerging electric power systems, 2 (21) (2020)

10. R.R. Singh, T.R. Chelliah, Enforcement of costeffective energy conservation on single-fed asynchronous machine using a novel switching strategy, Energy, 126 (2017)

11. M.-A. Enache, S. Enache, A. Campeanu, T. Cimpeanu, Considerations regarding modeling simulation and monitoring of dynamic regimes for asynchronous motors, Electrical and Power Engineering (EPE) International Conference and Exposition, (2014)

12. S. Ekinci, ZH. Lale, A. Demiroren. A didactic procedure for transient stability simulation of a 
multi-machine power system utilizing SIMULINK.

Int J Elect Eng Edu., 53 (1) (2016)

13. Meiyang Zuo, Hui Guo, Integrative modeling and simulation analysis of asynchronous motor and control system, International Conference on Electrical Machines and Systems (ICEMS), IEEE Xplore Digital Library (2011)

14. M. Yu. Pustovetov, A mathematical model of the threephase induction motor in three-phase stator reference frame describing electromagnetic and electromechanical processes, Dynamics of Systems, Mechanisms and Machines (Dynamics), IEEE Xplore Digital Library (Omsk, $15-17$ Nov. 2016)

15. M. Kral, R. Gono, Dynamic model of asynchronous machine, 18th International Scientific Conference on Electric Power Engineering (EPE), IEEE Xplore Digital Library, Kouty nad Desnou, Czech Republic (2017). 